\title{
Acute kidney injury in children with COVID- 19: a retrospective study
}

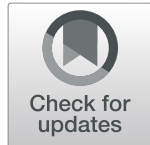

Jameela Abdulaziz Kari ${ }^{{ }^{*}+}$, Mohamed A Shalaby ${ }^{1 \dagger}$, Amr S Albanna ${ }^{2}$, Turki S Alahmadi ${ }^{3}$, Adi Alherbish ${ }^{4}$ and Khalid A Alhasan ${ }^{4}$

\begin{abstract}
Background: Acute kidney injury (AKI) is a complication of coronavirus disease 2019 (COVID-19). The reported incidence of AKI, however, varies among studies. We aimed to evaluate the incidence of AKI and its association with mortality and morbidity in children infected with severe acute respiratory distress syndrome coronavirus 2 (SARS-CoV-2) who required hospital admission.
\end{abstract}

Methods: This was a multicenter retrospective cohort study from three tertiary centers, which included children with confirmed COVID-19. All children were evaluated for AKI using the Kidney Disease Improving Global Outcomes (KDIGO) definition and staging.

Results: Of 89 children included, 19 (21\%) developed AKI (52.6\% stage I). A high renal angina index score was correlated with severity of AKI. Also, multisystem inflammatory syndrome in children (MIS-C) was increased in children with AKI compared to those with normal kidney function (15\% vs. $1.5 \%$ ). Patients with AKI had significantly more pediatric intensive care admissions (PICU) (32\% vs. $2.8 \%, p<0.001)$ and mortality ( $42 \%$ vs. $0 \%$, $p<0.001$ ). However, AKI was not associated with prolonged hospitalization (58\% vs. $40 \%, p=0.163$ ) or development of MIS-C (10.5\% vs. $1.4 \%, p=0.051)$. No patient in the AKI group required renal replacement therapy. Residual renal impairment at discharge occurred in $9 \%$ of patients. This was significantly influenced by the presence of comorbidities, hypotension, hypoxia, heart failure, acute respiratory distress, hypernatremia, abnormal liver profile, high C-reactive protein, and positive blood culture.

Conclusions: AKI occurred in one-fifth of children with SARS-CoV-2 infection requiring hospital admission, with one-third of those requiring PICU. AKI was associated with increased morbidity and mortality, and residual renal impairment at time of discharge.

Keywords: Acute Kidney Injury, COVID-19, Child, Multisystem Inflammatory Syndrome in Children

\section{Background}

Coronavirus disease 2019 (COVID-19) is a new disease that emerged in China in late 2019 [1]. Since then, it has caused an unprecedented health, social, and economic crisis. Similar to other coronaviruses, patients with COVID19 usually present with respiratory and gastrointestinal

\footnotetext{
* Correspondence: jkari@doctors.org.uk; jkari@kau.edu.sa

†Jameela A Kari and Mohamed A Shalaby contributed equally to this work. ${ }^{1}$ Pediatric Nephrology Center of Excellence, Department of Pediatrics, King Abdulaziz University, PO Box: 80215, 21589 Jeddah, Kingdom of Saudi Arabia Full list of author information is available at the end of the article
}

symptoms, but more severe cases progress to a systemic disease that affects almost all organs [2, 3].

Acute kidney injury (AKI) is a complication of COVID19 and the pathophysiology of AKI in COVID-19 appears to be multifactorial. The direct viral causes of AKI in COVID-19 are hypothesized as direct viral injury, dysregulated inflammation with cytokine storm, and vascular injury [4]. However, other factors found in similar diseases have also been described, including hypovolemia, heart failure (both right and left), sepsis, and dehydration $[5,6]$.

(c) The Author(s). 2021 Open Access This article is licensed under a Creative Commons Attribution 4.0 International License, which permits use, sharing, adaptation, distribution and reproduction in any medium or format, as long as you give appropriate credit to the original author(s) and the source, provide a link to the Creative Commons licence, and indicate if changes were made. The images or other third party material in this article are included in the article's Creative Commons licence, unless indicated otherwise in a credit line to the material. If material is not included in the article's Creative Commons licence and your intended use is not permitted by statutory regulation or exceeds the permitted use, you will need to obtain permission directly from the copyright holder. To view a copy of this licence, visit http://creativecommons.org/licenses/by/4.0/ The Creative Commons Public Domain Dedication waiver (http://creativecommons.org/publicdomain/zero/1.0/) applies to the data made available in this article, unless otherwise stated in a credit line to the data. 
The exact prevalence of AKI in patients with COVID19 is unknown. Initial reports from China reported a low prevalence of $0.5 \%$ [7]; however, in a later study, the prevalence rose to $19 \%$ [8]. Over time, and with a highly scrutinized data collection, the prevalence of AKI appears to be even higher. In two large multicenter studies conducted in New York, AKI was reported in 22.2 and $36.6 \%$ of 5700 patients (adults and children) and 5449 (adult only) patients, respectively $[9,10]$. In another cohort, AKI was reported in $46 \%$ of 3235 admitted patients [11]. The latter article reported that $68 \%$ of all critical care patients had AKI, and $20 \%$ of all admitted patients needed renal replacement therapy (RRT).

Similarly, the reported epidemiology of AKI in children infected with severe acute respiratory distress syndrome coronavirus 2 (SARS-CoV-2) is variable. In a cohort of 52 children in the UK, $46 \%$ had a serum creatinine level above the normal upper limit and $29 \%$ met the definition of AKI, but none required RRT [12]. In another multicenter study, $18 \%$ of critically ill children with COVID-19 had AKI [13]. These two studies reported a strong association between AKI and Multisystem Inflammatory Syndrome in Children (MIS-C). This is a severe form of COVID-19 presentation that usually occurs a few weeks after the initial (usually milder) symptoms [13].

In this multicenter study, we examined data from all children admitted with COVID-19 to estimate the prevalence of AKI and its associated risk factors, as well as the required care of those children.

\section{Methods}

This is a multicentric retrospective cohort study from 3 tertiary centers (King Abdulaziz University Hospital, King Khalid University Hospital, and East Jeddah General Hospital) in the Kingdom of Saudi Arabia (KSA).

\section{Inclusion criteria}

All children who were positive for COVID-19, determined by polymerase chain reaction (PCR) of nasal swab samples and requiring hospital admission at one of the participating centers between March 1st and mid-July 2020 , were included. Children were defined as $\leq 14$ years old. All included patients were considered ill because of the required hospital admission. All participating centers used the same visual triage checklist for acute respiratory infection in suspected cases to determine who needed screened using a nasopharyngeal swab.

All patients labeled as positive for COVID-19 had their nasopharyngeal andlor endotracheal swab samples screened by PCR. Patients were considered infected if the initial swab result was positive, or if it was initially negative with a positive repeat test. Only the first admission was considered for patients who had multiple hospital admissions.

\section{Exclusion criteria}

We excluded positive COVID-19 patients with insufficient data, those who were seen in the emergency department with positive swabs but did not require admission, or any patient with a previous admission for COVID-19. We also excluded neonates (defined as those aged $<28$ days at presentation) and patients with evidence of preexisting chronic kidney disease stages III-V.

\section{Data collection}

Clinical and laboratory data were collected and merged from electronic health records of all participating centers. Data included patient demographic information (age, gender, and nationality), anthropometric measures and centile, presenting symptoms and signs, associated comorbidities, and need for pediatric intensive care unit (PICU). For clinical information, we examined the severity of respiratory distress, blood pressure interpretation, oxygen saturation, need for oxygen therapy, and mechanical ventilation.

Renal function assessment was performed using the following data: baseline creatinine, baseline estimated glomerular filtration rate (eGFR), highest creatinine, and lowest eGFR recorded during the initial 7 days of admission. We calculated urine output (UOP) in children with available UOP data. We identified patients with AKI using the Kidney Disease Improving Global Outcomes (KDIGO) consensus definition [14]. KDIGO defines AKI as an increase in serum creatinine by $\geq 0.3 \mathrm{mg} / \mathrm{dL}(\geq$ $26.5 \mu \mathrm{mol} / \mathrm{L}$ ) within $48 \mathrm{~h}$; OR an increase in serum creatinine $\geq 1.5$ times the baseline level within the prior 7 days; OR a urine volume $\leq 0.5 \mathrm{~mL} / \mathrm{kg} /$ hour for the first $48 \mathrm{~h}$ of admission (for patients who had UOP information). We categorized AKI patients into 3 main stages. Stage I consisted of patients with an increase in serum creatinine by $\geq 0.3 \mathrm{mg} / \mathrm{dL}(\geq 26.5 \mu \mathrm{mol} / \mathrm{L})$, or an increase in serum creatinine to $\geq 1.5$ times the baseline level within the prior 7 days, and/or a UOP of $\leq 0.5 \mathrm{~mL} / \mathrm{kg} /$ hour over 6-12 h. Stage II patients had an increase in serum creatinine 2 to 2.9 times from the baseline level and/or a decrease in UOP of $\leq 0.5 \mathrm{~mL} / \mathrm{kg} / \mathrm{hour}$ for 12 to $24 \mathrm{~h}$. Stage III patients had an increase in serum creatinine by $\geq 353.6 \mathrm{mmol} \backslash \mathrm{L}$ or greater than 3 times the baseline level, a decrease in GFR to $<35 \mathrm{ml} \backslash \mathrm{min} \backslash 1.73 \mathrm{~m} 2$, and/or a decrease in UOP of $\leq 0.5 \mathrm{~mL} / \mathrm{kg} /$ hour for more than $24 \mathrm{~h}$.

We also calculated the renal angina index $(\mathrm{RAI}=1-$ 40) for all participants using the multiplication of both risk level and injury level. A score $\geq 8$ is considered a positive RAI [15]. Estimated glomerular filtration rate was calculated using the modified Schwartz formula 
[16]. Baseline creatinine was defined as the last creatinine within the previous 6 months prior to the PICU. For those patients admitted for the first time, we used an average GFR according to age, sex, and height of the child [17].

For any patient that required ICU admission, we calculated the Pediatric Risk of Mortality (PRISM version IV) during the first $24 \mathrm{~h}$ of ICU admission [18].

All laboratory workups were recorded and followed for identification of significantly associated hematological and $\backslash$ or laboratory abnormalities, such as significant anemia, leucopenia or leukocytosis, neutropenia or neutrophilia, thrombocytopenia, and disturbed coagulation profiles. Other associated laboratory abnormalities, such as hypernatremia, hyperkalemia, and high troponin levels were reported. Evidence of any associated infection (blood and urine culture) and the high acute phase reactants (Creactive protein and ferritin) were recorded and highlighted.

Clinical outcome indicators included mortality rate, abnormally high creatinine, high blood pressure, or proteinuria.

\section{Definitions}

Significant exposure to nephrotoxic medications (nephrotoxic injury negated by just-in-time action= NINJA score): exposure to 3 or more common nephrotoxic medications for 1 day or to aminoglycosides for 3 or more days [19].

Hypertension: 2 or more systolic and diastolic blood pressure readings at 2 different time points $>95$ th percentile for gender, age, and height.

Hypotension: 2 or more systolic and diastolic blood pressure readings at 2 different time points $<50$ th percentile for gender, age, and height.

Hyperkalemia: serum potassium level $>5.5 \mathrm{mmol} \backslash \mathrm{L}$.

Hypernatremia: serum sodium level $>146 \mathrm{mmol} \backslash \mathrm{L}$.

Anemia: a reduction of the hemoglobin concentration to 2 standard deviations below the mean, based on agespecific normal levels.

Leukocytosis and leucopenia: total leucocytic count higher than the mean normal value based on age.

Neutropenia: a neutrophilic count $<500 / \mathrm{mm}^{3}$.

Oliguria: a UOP $<0.5 \mathrm{ml} / \mathrm{kg} \backslash \mathrm{hr}$.

We used the World Health Organization definition for MIS-C and adolescents aged 0-19 years. Their criteria were fever for 3 days or more and two of the following: skin rash or signs of mucocutaneous inflammation hypotension or shock, features of myocardial dysfunction, evidence of coagulopathy, acute gastrointestinal problems, and elevated markers of inflammation, such as erythrocyte sedimentation rate, C-reactive protein, or procalcitonin, with evidence of COVID-19 and no other obvious microbial cause of inflammation [20].
The study was approved by the Biomedical Ethics Research Committees of the three recruiting centers (King Abdulaziz University -faculty of medicine, King Khalid University - medical college, and East Jeddah General Hospital,). Consent from participants was not required as this was a retrospective study using data collected for routine clinical practice.

\section{Statistical analysis}

All analyses were performed using STATA (StataCorp. 2011. Stata Statistical Software: Release 12. College Station, TX). The proportion and mean for dichotomous and continuous variables, respectively, were measured to describe a patient's characteristics. The association between AKI development and different outcomes (prolonged hospitalization, ICU admission, and mortality) was measured using the chi-square test. Multiple regression analysis was also performed to adjust for age, sex, and the presence of comorbidities. Predictors of residual renal impairment at discharge was measured using the chi-square test. Statistical significance was determined using a $95 \%$ confidence interval and a $p$-value of 0.05 .

\section{Results}

Eighty-nine children admitted with a confirmed diagnosis of COVID-19 were included in this study. Of these, 19 (21\%) developed AKI upon admission. Patients with AKI were younger than those with normal kidney function. Most of the children in both groups tended to be overweight with a median body mass index in the 91st percentile. Children with AKI had an increased number of comorbidities compared to patients with normal kidney function (Table 1).

None of the admitted patients had chronic renal impairment and had almost normal baseline levels of creatinine and eGFR. Figure 1 shows the average change in serum creatinine and eGFR levels during admission of patients who did and did not develop AKI.

Using KDIGO staging for AKI, $58 \%$ of patients with AKI had stage I, $31.5 \%$ had stage II, and $10.5 \%$ had stage III. Their RAI score was $<8$ (insignificant) in 10 out of the 11 children with stage I AKI. However, all children with AKI stages II and III had a significant RAI score $(\geq 8)$, and all children with stage III AKI had a maximum RAI score of 40 (Table 2).

$15 \%$ of AKI patients (all with stage III AKI) presented with the full diagnostic criteria of MIS-C, compared to only $1.5 \%$ of non-AKI children (Fig. 2). Furthermore, renal function deteriorated earlier in children with stage II and III compared to children with stage I AKI. The NINJA indicator of significant exposure to nephrotoxic 
Table 1 Baseline patient demographics and disease characteristics

\begin{tabular}{|c|c|c|c|c|c|}
\hline \multirow[t]{2}{*}{ Characteristics } & \multicolumn{2}{|c|}{$\begin{array}{l}\text { Acute Kidney Injury } \\
\text { (No. 19) }\end{array}$} & \multicolumn{2}{|c|}{$\begin{array}{l}\text { Normal Renal Function } \\
\text { (No. 70) }\end{array}$} & \multirow[t]{2}{*}{$\begin{array}{l}P \\
\text { Value }\end{array}$} \\
\hline & Estimate & $95 \% \mathrm{Cl}$ & Estimate & $95 \% \mathrm{Cl}$ & \\
\hline Age (mean, months) & 54.6 & $30.0-79.3$ & 74.7 & $61.1-88.3$ & 0.1676 \\
\hline (median, months) & 24 & $11.5-111.4$ & 72 & $36.0-92.7$ & \\
\hline Male sex (\%) & 47.4 & $24.4-71.1$ & 40.0 & $28.5-52.4$ & 0.563 \\
\hline Saudi nationality (\%) & 47.4 & $24.4-71.1$ & 54.3 & $41.9-66.3$ & 0.592 \\
\hline Length (mean, cm) & 85 & 72-99 & 107 & $98-115$ & 0.0140 \\
\hline (median, cm) & 80 & $66.6-101$ & 104 & $93.3-117$ & \\
\hline (mean, percentile) & 9.7 & $0-21.1$ & 37.2 & $27.7-46.8$ & \\
\hline (median, percentile) & 0.4 & $0.3-2$ & 25 & $2.0-50.0$ & \\
\hline BMI (mean kg/m²) & 19.4 & $16.1-22.8$ & 20.8 & $18.7-22.9$ & 0.5296 \\
\hline (median kg/m²) & 17.9 & $14.7-22.2$ & 18.9 & $16.4-22.2$ & \\
\hline (mean, percentile) & 61.3 & $41.4-81.2$ & 66.2 & $56.3-76.2$ & \\
\hline (median, percentile) & 91 & $20.1-98.5$ & 91.0 & $75.0-98.0$ & \\
\hline Contact with COVID patients & 78.9 & $54.4-93.9$ & 82.9 & $72.0-90.8$ & 0.694 \\
\hline Recent travel & 10.5 & $1.3-33.1$ & 4.3 & $0.9-12.0$ & 0.295 \\
\hline Comorbidities $^{\mathrm{a}}(\%)$ & 63.2 & $38.4-83.7$ & 18.6 & $10.3-29.7$ & $<0.001$ \\
\hline
\end{tabular}

Abbreviations: $B M I$ body mass index, $C l$ confidence interval, $\mathrm{cm}$ centimeter

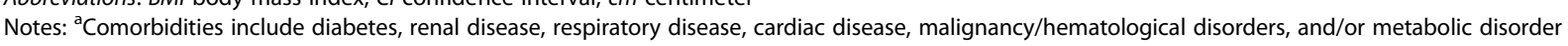

medications was more frequently positive in patients with stage II and III AKI (87.5\%) than in those with either stage I AKI (9.1\%) or normal renal function $(12.9 \%)(p<0.001)$. Most patients with AKI $(95 \%)$ were non-oliguric and there was no evidence of hypervolemia in any patient. RRT was not prescribed for any patient with AKI (Table 2).

AKI was significantly associated with more frequent ICU admission (32\% vs. $2.8 \%, p<0.001)$ and mortality ( $42 \%$ vs. $0 \%, p<0.001)$, but not with prolonged hospitalization ( $58 \%$ vs. $40 \%, p=0.163$ ) or development of MIS-C ( $10.5 \%$ vs. $1.4 \%, p=0.051)$ compared to patients with normal kidney function (Fig. 2). After adjustment for age, sex, and the presence of comorbidities, AKI was still significantly associated with mortality (adjusted OR: 14.6, $p=0.041$ ) and ICU admission (adjusted OR: 10.1, $p=0.009$ ). Residual renal impairment at discharge occurred in $9 \%$ of our population, which was influenced by the following predictive factors: presence of comorbidities $(p=0.023)$, hypotension $(p<0.001)$, hypoxia $(p=0.02)$, heart failure $(p=0.001)$, adult respiratory distress syndrome (ARDS) $(p=0.005)$, hypernatremia $(p=0.011)$, abnormal liver profile $(p=0.046)$, high $C$ reactive protein $(p=0.033)$, and positive blood culture $(p=0.002)$ (Table 3).

\section{Discussion}

The emergence of COVID-19 in December 2019 prompted many pediatric nephrology units to prepare for an increased demand for dialysis and PICU services.
It has been determined that children seem to be less severely affected by this virus than adults. The surge in hospitalized adult patients requiring dialysis caused many resources previously allocated to pediatrics to be diverted to adults. Position statements and articles were published to inform pediatric nephrologists about the proper utilization of their resources $[5,21]$. Nonetheless, an exact estimate of the prevalence of AKI in children hospitalized with COVID-19 remains essential to guide such decisions.

Our study examined eighty-nine children who were hospitalized with COVID-19. Of these, $21 \%$ developed AKI, which is lower than previously reported by Stewart et al. in their cohort of 52 children admitted to the Great Ormond Street Hospital [12]. In their report, approximately $29 \%$ of children developed AKI. The discrepancies between our findings and those of Stewart et al. could be due to the different definitions of AKI used. Of note is that Stewart et al. used the British Association of Pediatric Nephrology (BAPN) diagnostic criteria to define AKI. Another factor that may explain the lower prevalence of AKI in our cohort could be the lower incidence of MIS-C. In our cohort, only $15 \%$ of AKI patients met the full diagnostic criteria of MIS-C associated with SARS-Cov-2, while in the study by Stewart et al., $73 \%$ of those with AKI met the criteria of MIS-C associated with SARS-Cov-2 [22]. The incidence of MIS-C was marginally higher, albeit not significantly higher, when compared with that in children with normal kidney function ( $\mathrm{p}=0.051)$. This could be explained by the small number of children analyzed." 


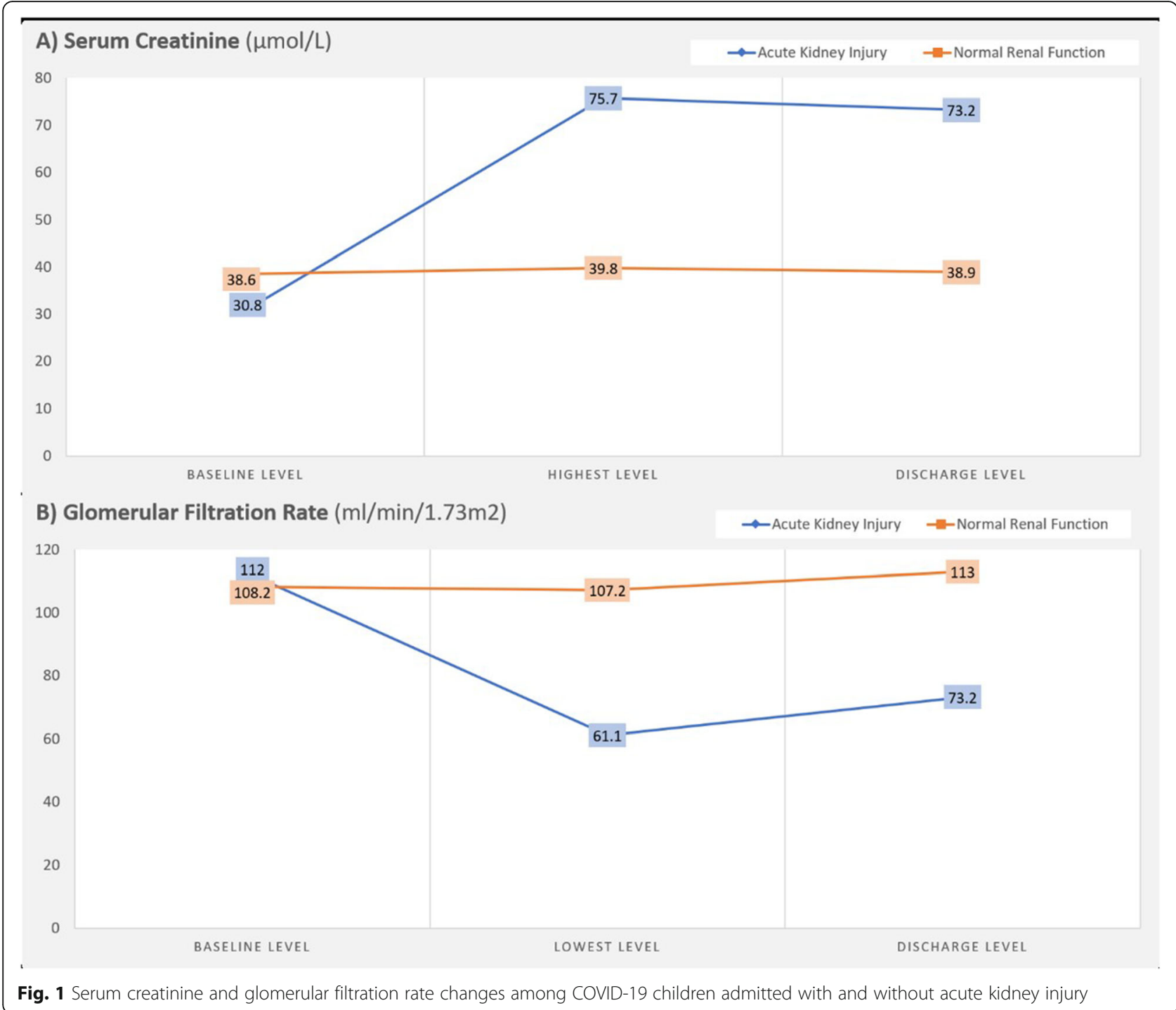

One of the most remarkable aspects of AKI in this study is its asymptomatic nature. In our patients, $95 \%$ had no oliguria, none developed hypervolemia, and none required RRT. A decline in mean GFR reached $61.1 \mathrm{ml} / \mathrm{min} / 1.73 \mathrm{~m}^{2}$ at its lowest, a level not known to cause considerable electrolyte or volume disturbances. The time to worsening renal function was shorter in patients with stage II and III AKI, reaching a mean of $6 \mathrm{~h}$. Of note is that the RAI score was high in all cases of stage II and III AKI, and a negative score was found in $90 \%$ of stage I patients. Despite the asymptomatic nature of AKI in this cohort, its early identification and prevention is important considering its association with higher morbidity and mortality. The association between AKI and PICU admission could be explained by a worsening general condition and hemodynamic instability necessitating ICU admission, and hence an increasing incidence of AKI. Nonetheless, AKI cannot be excluded as the sole cause of increased PICU admissions, especially in its more severe forms [23, 24]. Presence of comorbidities was important in those who developed AKI and those who ended with residual renal impairment at discharge. Hence, it is important to follow UOP and creatinine carefully in children infected with SARS-CoV-2, especially if they have comorbid conditions, such as respiratory diseases, cardiac diseases, hematological disorders, renal diseases, diabetes, and malignancies. There was also a tendency for AKI to happen at a relatively younger age.

As stated above, $9 \%$ of our study population developed residual renal impairment at the time of discharge. Factors associated with residual renal impairment were either related to decreased tissue perfusion (hypotension, heart failure, hypoxia, acute respiratory syndrome), sepsis (high C-reactive protein, positive blood culture), worsening clinical condition (hypernatremia, increased liver enzymes), or comorbidities. What intrigued us was the failure of dehydration to reach statistical significance 
Table 2 Parameters related to nephrology assessment of COVID-19 children admitted with acute kidney injury (19 children)

\begin{tabular}{|c|c|c|c|}
\hline & \multicolumn{3}{|l|}{ Status of renal function } \\
\hline & Normal (70 children) & KDIGO I (11 children) & KDIGO II \& III (8 children) \\
\hline \multicolumn{4}{|l|}{ RAI (number (\%)) } \\
\hline Score <8 (non-significant) & $70(100 \%)$ & $10(90.9)$ & 0 \\
\hline Score 8 & 0 & $1(9.1)$ & $5(62.5)$ \\
\hline Score 40 & 0 & 0 & $3(37.5)$ \\
\hline NINJA-positive (number (\%)) & $9(12.9)$ & $1(9.1)$ & $7(87.5)$ \\
\hline Time to worsening of renal function ${ }^{a}$ (mean (SD), hrs.) & - & $12.8(13.8)$ & $6(8.6)$ \\
\hline \multicolumn{4}{|l|}{ Nephrotoxic drug administration (number (\%)) } \\
\hline None & $60(85.7)$ & $9(81.8)$ & $1(12.5)$ \\
\hline One drug & $5(7.1)$ & $2(18.2)$ & $4(50)$ \\
\hline Multiple drugs & $5(7.1)$ & 0 & $3(37.5)$ \\
\hline Duration of nephrotoxic therapy (mean (SD), days) & $6.1(3.5)$ & $3.5(2.1)$ & $5(2.4)$ \\
\hline Nephrology referral (number (\%)) & 0 & 0 & $3(37.5)$ \\
\hline Oliguria (number (\%)) & 0 & 0 & $1(12.5)$ \\
\hline Hypervolemia (number (\%)) & 0 & 0 & 0 \\
\hline Use of RRT (number (\%)) & 0 & 0 & 0 \\
\hline Residual renal impairment at discharge (number (\%)) & 0 & $3(27.3)$ & $5(62.5)$ \\
\hline
\end{tabular}

Abbreviations: KDIGO Kidney Disease Improving Global Outcomes, RAI renal angina index, NINJA nephrotoxic injury negated by just-in-time action, SD standard deviation; $R R T$ renal replacement therapy

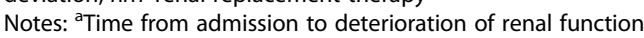

despite it being reported as an important culprit of AKI caused by SARS-CoV-2, a disease known to cause diarrhea in $8.1 \%$ of children [22]. This can be explained by the possibility of rapid detection and the early correction of dehydration before it contributed to an increased risk of residual renal impairment.
One of the limitations of this study is its small population size. Fortunately, children infected with SARS-CoV2 do not need to be hospitalized as frequently as adults, an obstacle interfering with all pediatric epidemiological studies in COVID-19. We attempted to overcome this limitation by forming a collaboration between three

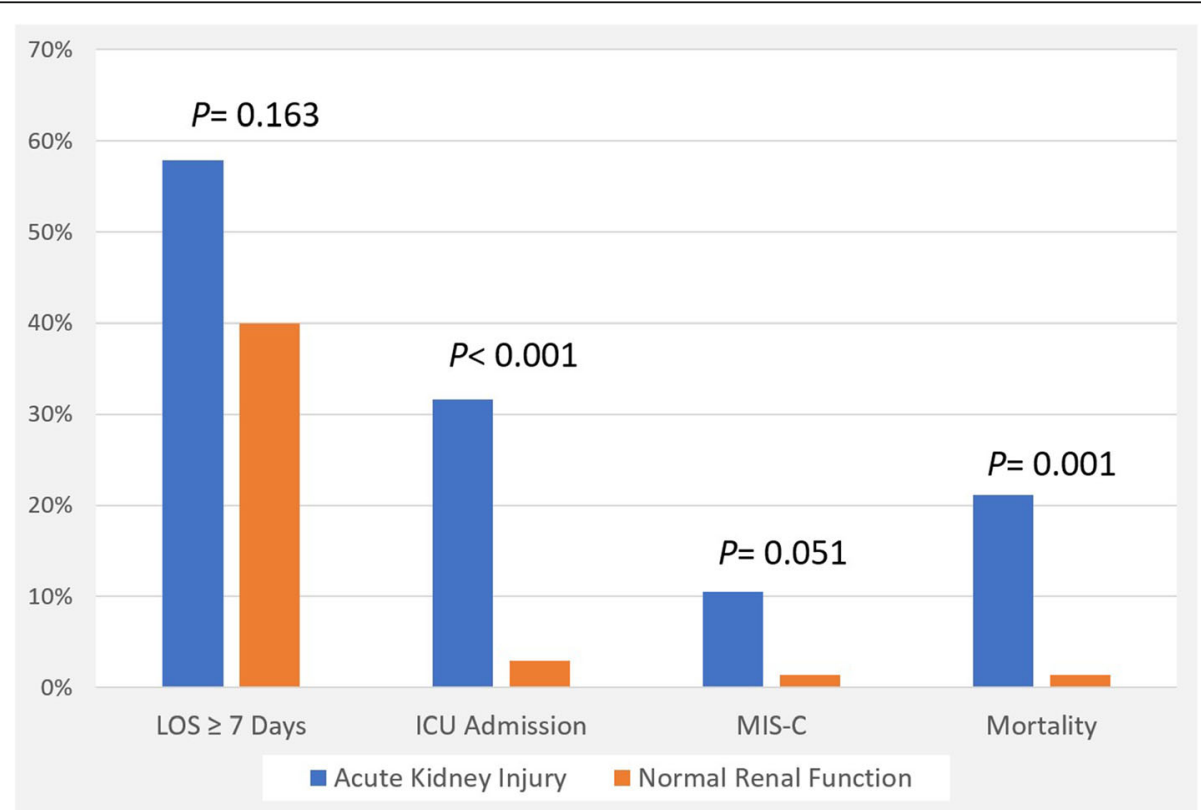

Fig. 2 COVID-19 related clinical outcomes associated with acute kidney injury 
Table 3 Factors associated with residual renal impairment at discharge of COVID-19 children

\begin{tabular}{|c|c|c|c|}
\hline Factors & & $\begin{array}{l}\text { Residual Renal } \\
\text { Impairment }^{\mathrm{a}}(\%)\end{array}$ & $\begin{array}{l}P \\
\text { Value }\end{array}$ \\
\hline \multirow[t]{2}{*}{ Age } & $\geq 5$ years & 10.4 & 0.350 \\
\hline & $<5$ years & 5.0 & \\
\hline \multirow[t]{2}{*}{ Sex } & Male & 8.1 & 0.806 \\
\hline & Female & 9.6 & \\
\hline \multirow[t]{2}{*}{ Nationality } & Saudi & 10.6 & 0.565 \\
\hline & Non-Saudi & 7.1 & \\
\hline \multirow[t]{2}{*}{ Comorbidities $^{b}$} & No & 4.7 & 0.023 \\
\hline & Yes & 20.0 & \\
\hline \multirow[t]{2}{*}{ Dyspnea } & No & 9.1 & 0.966 \\
\hline & Yes & 8.8 & \\
\hline \multirow[t]{2}{*}{$\mathrm{Gl}_{\text {symptoms }}{ }^{\mathrm{C}}$} & No & 9.2 & 0.895 \\
\hline & Yes & 8.3 & \\
\hline \multirow[t]{2}{*}{ Skin rash } & No & 8.1 & 0.134 \\
\hline & Yes & 33.3 & \\
\hline \multirow[t]{3}{*}{ Arterial BP } & Normal & 6.9 & $<$ \\
\hline & High & 0 & \\
\hline & Low & 75.0 & \\
\hline \multirow[t]{2}{*}{ Hypoxia } & No & 5.6 & 0.020 \\
\hline & Yes & 23.5 & \\
\hline \multirow[t]{2}{*}{ Dehydration } & No & 8.2 & 0.588 \\
\hline & Yes & 12.5 & \\
\hline \multirow{2}{*}{$\begin{array}{l}\text { Heart failure (clinical } \\
\text { signs) }\end{array}$} & No & 8.0 & 0.001 \\
\hline & Yes & 100 & \\
\hline \multirow[t]{4}{*}{ Chest radiograph } & Normal & 7.6 & 0.005 \\
\hline & $\begin{array}{l}\text { Mild } \\
\text { Pneumonia }\end{array}$ & 5.6 & \\
\hline & $\begin{array}{l}\text { Severe } \\
\text { Pneumonia }\end{array}$ & 0 & \\
\hline & ARDS & 66.7 & \\
\hline \multirow[t]{2}{*}{ Anemia } & No & 7.0 & 0.386 \\
\hline & Yes & 12.5 & \\
\hline \multirow[t]{3}{*}{ WBC } & Normal & 4.0 & 0.164 \\
\hline & Low & 18.2 & \\
\hline & High & 14.3 & \\
\hline \multirow[t]{3}{*}{ Serum sodium } & Normal & 5.3 & 0.011 \\
\hline & Low & 25.0 & \\
\hline & High & 33.3 & \\
\hline \multirow[t]{2}{*}{ Hyperkalemia } & No & 9.6 & 0.425 \\
\hline & Yes & 0 & \\
\hline \multirow[t]{2}{*}{ LFT } & Normal & 6.0 & 0.046 \\
\hline & Abnormal & 21.1 & \\
\hline \multirow[t]{2}{*}{ CRP } & Normal & 3.8 & 0.033 \\
\hline & High & 17.1 & \\
\hline
\end{tabular}

Table 3 Factors associated with residual renal impairment at discharge of COVID-19 children (Continued)

\begin{tabular}{llll}
\hline Factors & & $\begin{array}{l}\text { Residual Renal } \\
\text { Impairment }^{\mathbf{a}} \text { (\%) }\end{array}$ & $\begin{array}{l}\boldsymbol{P} \\
\text { Value }\end{array}$ \\
\hline Troponin I & Normal & 9.4 & 0.262 \\
& High & 20.0 & \\
Blood culture & Negative & 6.8 & $\mathbf{0 . 0 0 2}$ \\
& Positive & $\mathbf{4 2 . 9}$ & \\
\hline
\end{tabular}

Abbreviations: Gl gastrointestinal, $B P$ blood pressure, ARDS acute respiratory distress syndrome, WBC white blood cells, LFT liver function test, CRP $C$-reactive protein

Note: ${ }^{\mathrm{a}}$ Abnormal renal function at the time of discharge. ${ }^{\mathrm{b}}$ Comorbidities include diabetes, renal disease, respiratory disease, cardiac disease, oncology/ hematology disorders, and/or metabolic disorder. 'Diarrhea or vomiting

pediatric hospitals, reaching a cohort of 89 children. Another limitation is the retrospective nature and short duration of this study. It would be interesting to follow those who had residual renal impairment at the time of discharge to see whether it improves with time or translates into permanent chronic kidney disease.

\section{Conclusions}

In conclusion, in the setting of COVID-19, AKI occurred in approximately one-fifth of our hospitalized children, and more than one-third of those required PICU admission. AKI is more commonly found in younger children and in those with comorbid conditions. AKI is associated with increased mortality and morbidity. A small proportion of children with AKI can develop residual renal impairment at the time of discharge. Nonetheless, it tends to be milder than in adults, with a lower incidence of oliguria and less need for RRT.

\section{Abbreviations}

ARDS: Acute respiratory distress syndrome; COVID-19: Coronavirus disease 2019; eGFR: Estimated glomerular filtration rate; KDIGO: Kidney Disease Improving Global Outcomes; LFT: Liver function test; MIS-C: Multisystem inflammatory syndrome in children; NINJA: Nephrotoxic injury negated by just-in-time action; PCR: Polymerase chain reaction; PICU: Pediatric intensive care admissions; RAl: Renal angina index; RRT: Renal replacement therapy; UP: Urine output

\section{Acknowledgements}

The authors acknowledge the Deanship of Scientific Research (DSR) at King Abdulaziz University, Jeddah, KSA for technical and financial support (grant number GCV19-38- 1441.) This work was also supported by the College of Medicine, Research Center, Deanship of Scientific Research, King Saud University, Riyadh, KSA.

\section{Authors' contribution}

JAK: Idea, application for grant, coordination of the study, writing and editing the manuscript. MAS: Coordination of the study between three centers, writing and editing the manuscript. ASA; Analysis of the data, writing up the results and revising the manuscript. TA:: Writing and editing the manuscript. AA; Writing and editing the manuscript. KAA; Coordination of the study at King Saud University, writing and editing the manuscript. All authors have read and approved the manuscript. 


\section{Funding}

This work was supported by the Deanship of Scientific Research (DSR) at King Abdulaziz University, Jeddah [grant number GCV19-38- 1441]. The funding bodies played no role in the design of the study and collection, analysis, and interpretation of data and in writing the manuscript.

\section{Availability of data and materials}

The datasets used and/or analysed during the current study available from the corresponding author on reasonable request."

\section{Declarations}

\section{Ethics approval and consent to participate}

The study was approved by the Biomedical Ethics Research Committees of the three recruiting centers (King Abdulaziz University -faculty of medicine, King Khalid University - medical college, and East Jeddah General Hospital). Consent from participants was not required as this was a retrospective study using data collected for routine clinical practice.

\section{Consent for publication}

Not required.

\section{Competing interests}

The authors report no conflicts of interest.

\section{Author details}

${ }^{1}$ Pediatric Nephrology Center of Excellence, Department of Pediatrics, King Abdulaziz University, PO Box: 80215, 21589 Jeddah, Kingdom of Saudi Arabia ${ }^{2}$ King Abdullah International Medical Research Center, King Saud Bin Abdulaziz University for Health Sciences, Jeddah, Kingdom of Saudi Arabia. ${ }^{3}$ Department of Pediatrics, King Abdulaziz University and Faculty of Medicine in Rabigh, Jeddah, Kingdom of Saudi Arabia. ${ }^{4}$ Pediatrics Department, College of Medicine, King Saud University, Riyadh, Kingdom of Saudi Arabia.

\section{Received: 26 August 2020 Accepted: 5 May 2021}

\section{Published online: 31 May 2021}

\section{References}

1. Huang C, Wang Y, Li X, Ren L, Zhao J, Hu Y, Zhang L, Fan G, Xu J, Gu X, Cheng Z, Yu T, Xia J, Wei Y, Wu W, Xie X, Yin W, Li H, Liu M, Xie Xiao,Y,Gao,H,Guo,L, Wang J, Jiang G, Gao R, Jin Z, Wang Q,J., and Cao B. Clinical features of patients infected with 2019 novel coronavirus in Wuhan, China. Lancet. 2020;395:497-506.

2. Ding Y, Yan,H., and Guo W. Clinical Characteristics of Children With COVID19: A Meta-Analysis. Front Pediatr. 2020;8:431.

3. Docherty $A B$, Harrison EM, Green CA, Hardwick HE, Pius R, Norman L, Holden KA, Read JM, Dondelinger F, Carson G, Merson L, Lee J, Plotkin D, Halpin Sigfrid,L, Jackson S, Gamble C, Horby C, Nguyen-Van-Tam PW, Ho JS, Russell A, Dunning CD, Openshaw J, Baillie PJ,J.K., and Semple MG. Features of 20â€\%०133 UK patients in hospital with covid-19 using the ISARIC WHO Clinical Characterisation Protocol: prospective observational cohort study. BMJ. 2020;369:m1985.

4. Batlle D, Soler MJ, Sparks MA, Hiremath S, South AM, Welling PA, Swaminathan S. Acute Kidney Injury in COVID-19: Emerging Evidence of a Distinct Pathophysiology. J Am Soc Nephrol. 2020;31:1380-3.

5. Deep A, Bansal M, Ricci Z. Acute Kidney Injury and Special Considerations during Renal Replacement Therapy in Children with Coronavirus Disease-19: Perspective from the Critical Care Nephrology Section of the European Society of Paediatric and Neonatal Intensive Care. Blood Purif. 2021;50:15060. https://doi.org/10.1159/000509677.

6. Ronco C, Reis T. Kidney involvement in COVID-19 and rationale for extracorporeal therapies. NatRevNephrol. 2020;16:308-10.

7. Guan WJ, Zhong NS. Clinical Characteristics of Covid-19 in China. Reply. NEnglJ Med. 2020;382:1861-2.

8. Xiao G, Hu H, Wu F, Sha T, Zeng Z, Huang Q, Li H, Han J, Song W, Chen Z, Cai S, Xiao G, Hu H, Wu F, Sha T, Zeng Z, Huang Q, Li H, Han J, Song W, Chen Z, Cai S. Acute kidney injury in patients hospitalized with COVID-19 in Wuhan, China: A single-center retrospective observational study. 2021. https://doi.org/10.12122/j.issn.1673-4254.2021.02.01.

9. Richardson S, Hirsch JS, Narasimhan M, Crawford JM, McGinn T, Davidson KW, Barnaby DP, Becker LB, Chelico JD, Cohen SL, Cookingham J, Coppa K,
Diefenbach MA, Dominello AJ, Duer-Hefele J, Gitlin Falzon,L, Hajizadeh J, Harvin N, Hirschwerk TG, Kim DA, Kozel EJ, Marrast ZM, Mogavero LM, Osorio JN, Qiu GA,M., and Zanos TP. Presenting Characteristics, Comorbidities, and Outcomes Among 5700 Patients Hospitalized With COVID-19 in the New York City Area. JAMA. 2020; 323:2052-2059.

10. Hirsch JS, Ng JH, Ross DW, Sharma P, Shah HH, Barnett RL, Hazzan AD, Fishbane S, Jhaveri KD. Acute kidney injury in patients hospitalized with COVID-19. Kidney Int. 2020;98:209-18.

11. Chan L, Chaudhary K, Saha A, Chauhan K, Vaid A, Zhao S, Paranjpe I, Somani S, Richter F, Miotto R, Lala A, Kia A, Timsina P, Li L, Freeman R, Chen R, Narula J, Just AC, Horowitz C, Fayad Z, Cordon-Cardo C, Schadt E, Levin MA, Reich DL, Fuster V, Murphy B, He JC, Charney AW, Böttinger EP, Glicksberg BS, Coca SG, Nadkarni GN. Mount Sinai COVID Informatics Center (MSCIC) (2021). Acute Kidney Injury in Hospitalized Patients withCOVID-19. J Am Soc Nephrol. 2021:32(1):151-60. https://doi.org/10.1681/ASN.2020050615.

12. Stewart DJ, Hartley JC, Johnson M, Marks SD, du PP, Stojanovic J. Renal dysfunction in hospitalised children with COVID-19. Lancet Child AdolescHealth. 2020;4:e28-9.

13. Gonź، lez-Dambrauskas S, Vísquez-Hoyos P, Camporesi A, Dlaz-Rubio F, Pil \pm eres-Olave BE, Fernl‘ndez-Sarmiento J, Gertz S, Harwayne-Gidansky I, Chse Pietroboni,P, Shein SL, Urbano J, Zemanate Wegner,A,E., and Karsies T. Pediatric Critical Care and COVID19. Pediatrics. 2020:146(3):e20201766. https://doi.org/10.1542/peds.2020-1766.

14. Khwaja A. KDIGO clinical practice guidelines for acute kidney injury. Nephron Clin Pract. 2012;120:c179-84.

15. Matsuura R, Srisawat N, Claure-Del GR, Doi K, Yoshida T, Nangaku M, Noiri E. Use of the Renal Angina Index in Determining Acute Kidney Injury. Kidney Int Rep. 2018;3:677-83.

16. Schwartz GJ, Work DF. Measurement and estimation of GFR in children and adolescents. Clin J Am Soc Nephrol. 2009;4:1832-43.

17. Zappitelli M, Parikh CR, kcan-Arikan A, Washburn KK, Moffett BS, Goldstein SL. Ascertainment and epidemiology of acute kidney injury varies with definition interpretation. Clin J Am Soc Nephrol. 2008:3:948-54.

18. Pollack MM, Holubkov R, Funai T, Dean JM, Berger JT, Wessel DL, Meert K, Berg RA, Newth CJ, Harrison RE, Carcillo J, Jenkins Dalton,H,Shanley,T,T.L., and Tamburro R. The Pediatric Risk of Mortality Score: Update 2015. Pediatr Crit Care Med. 2016:17:2-9.

19. Goldstein SL, Dahale D, Kirkendall ES, Mottes T, Kaplan H, Muething S, Askenazi DJ, Henderson T, Dill L, Somers MJG, Kerr J, Gilarde J, Zaritsky J, Bica V, Brophy PD, Misurac J, Hackbarth R, Steinke J, Mooney J, Ogrin S, Chadha V, Yonekawa Warady,B,Ogden,R,Hoebing,W,Symons,J, Menon K, Abrams S, Sutherland L, Weng S, Zhang P,F., and Walsh K. A prospective multi-center quality improvement initiative (NINJA) indicates a reduction in nephrotoxic acute kidney injury in hospitalized children. Kidney Int. 2020;97: $580-8$.

20. Qorl Health organization. Multisystem inflammatory syndrome in children and adolescents with COVID-19. WHO; 2020. pp. 1-3. (GENERIC) Ref, Type. Electronic Citation.

21. Raina R, Chakraborty R, Sethi SK, Bunchman T. Kidney Replacement Therapy in COVID-19 Induced Kidney Failure and Septic Shock: A Pediatric Continuous Renal Replacement Therapy [PCRRT] Position on Emergency Preparedness With Resource Allocation. Front Pediatr. 2020;8:413.

22. Mantovani A, Rinaldi E, Zusi C, Beatrice G, Saccomani MD, Dalbeni A. Coronavirus disease 2019 (COVID-19) in children and/or adolescents: a meta-analysis. Pediatr Res. 2021;89(4):733-7. https://doi.org/10.1038/s41390020-1015-2

23. Kari JA, Alhasan KA, Shalaby MA, Khathlan N, Safdar OY, Al Rezgan SA, El DS, Albanna AS. Outcome of pediatric acute kidney injury: a multicenter prospective cohort study. Pediatr Nephrol. 2018:33:335-40.

24. Kaddourah A, Basu RK, Bagshaw SM, Goldstein SL. Epidemiology of Acute Kidney Injury in Critically III Children and Young Adults. NEnglJ Med. 2017; 376:11-20.

\section{Publisher's Note}

Springer Nature remains neutral with regard to jurisdictional claims in published maps and institutional affiliations. 